\section{Culture in Translation: A Comprehensive Study}

\section{K.A. Nagodawithana}

\section{Abstract}

The process of translation involves rendering a text written in one language with the use of the symbols of another language. This act of translation is governed by a myriad of textual and extra-textual elements. Amongst them, culture has a profound impact on the process of translation. The succulent dishes catering to an individual's taste palate to clothes donned; culture showcase a unique combination of attributes that construct a formidable deterrent for the translator. Hence, the present study seeks to clarify the position of the culture within the translation process, the magnitude of impact on translators and readership, and the strategies adopted by translators to overcome the obstacles posed by cultural distinctions to reap a productive translation. A highly qualitative approach consisting of in-depth, semi-structured interviews was conducted with six individuals actively involved in translation. The garnered data were evaluated and reviewed under the Thematic Analysis method to reach conclusions. The analyzed data revealed that during translation, the contact between two different cultural systems inevitably leads to a confrontation amid two heterogeneous value systems deeply embedded within the respective communities. As a result, culture portrays a dominant figurine, inadvertently endorsing the translators to act as cultural -mediators during translation. In the course, translators adopt a plethora of techniques manipulating culture-specific dimensions up to a certain extent to achieve a translation where the message received by the receptor is substantially the same as the message received via the Source Text.

Keywords: Cultural-mediators, Culture, Languages, Translation, Translators
Faculty of Graduate

Studies,

University of Kelaniya,

Sri Lanka

anuththaranagodawithana@gmail.com 


\section{Original Article}

\section{INTRODUCTION}

Conventionally, translation is defined as the act of rendering a message written in one language in another. Hence, in an ideal context, the translator ought to (re)write the original text - whereas, in reality, the process of translation is quite more intricate than that. The heterogeneous nature of the textual and extra-textual elements of the Source and Target Texts together with the evolution of the communication practices, weave a Gordian knot for the translator to work upon; for instance, the paralinguistic elements of the Source Text - the vocal cues signifying an unmissable lexical meaning such as the body language, intonation and even the idiosyncratic inflections innate to an individual generate an extra layer of obstruction for the translator.

Such textual elements demand that the translator concentrates on each textual constituent of the texts involved in translation, whilst extra-textual factors govern the said text-bound elements' behavior. For instance, the cultural dimensions reflected in the Source and Target Texts predominantly impact the functional behaviors of the lexical components even though it resides externally to the linguistic elements of the text. In reference to the exemplar mentioned above, it could be elaborated that even the paralanguage visible in a text is culture-specific. For instance, high pitched or breathy intonations rampant in conversations with Arabs and Latinas to tongue clicking seen in South Africa implying hesitation are inherent to the respective cultures.

The orientation of culture within the scope of translation has thus been a constant altercation since the cultural turn in translation. ${ }^{1}$ The positioning of culture within the process of translation, the magnitude of impact culture has on the linguistic composition of the Source and Target Texts, the construction and reconstruction of cultural attributes during translation as well as the translator's choice of texts have been persisting at the forefront of the discourse on translation of culture. Newmark (2001) stated that "now whilst some see culture as the essence of translation, I see culture as the greatest obstacle to translation, at least to the achievement of an accurate and decent translation" (p. 328). Likewise, culture has often leveraged the practice of translation, both implicitly and explicitly.

Culture is the web that includes ways of living, manners, beliefs, values, customs, aesthetic standards, social institutions, and communication styles that a group of people has developed to maintain its survival in their surroundings. In other words, culture encompasses the characteristics that

\footnotetext{
1 A metaphor adapted by Bassnett and Lefevere (1990), which initially referred to the move from translation centered on texts to translation on culture.
} 
make an individual unique, leading to a construction of their own identity in a multi-dimensional reality. Jahoda (2012) perfectly surmises the phenomenon of culture as "patterns, explicit and implicit, of and for behavior acquired and transmitted by symbols, constituting the distinctive achievements of human groups"(p. 291). Hence, an individual exhibits a plethora of features inherent to the culture they are accustomed to. As language is an expression of such intrinsic cultural attributes and the individuality of the speaker, translation inevitably becomes a mediator between the two cultures. The act of translation thus ensues within a cultural context particular to the source text, and the translator mediates to transform the said cultural situation to the comprehension of the target audience - "the translator takes on the role of a mediator between different cultures, each of which has its own vision of reality, ideologies, myths and so on" (Babee et al., 2014, p. 16). For instance, in translating Shakespeare's well-liked metaphor of the sonnet 18, 'Shall I compare thee to a summer's day?', choosing a cultural equivalent in a target culture where climatic differences contrast the notion of the Source Text is quite challenging to achieve. The translator attempts to bridge the gap between the two cultures by selecting an appropriate and target culture-oriented equivalent to fashion a meaningful translation.
Hence, this cultural asymmetry visible amongst two linguistic communities strongly influences and reflects in a translation. In the opinions of Nida (2015), "the person who is engaged in translating from one language into another ought to be constantly aware of the contrast in the entire range of culture represented by the two languages" (p. 194). Specifically, the translator needs to accommodate the manifestation of the culture-specific concept of the Source Text without any distortion to the notion transferred, and it should construct the exact replica within the audience's comprehension in his wording preferences. In such a context, the questions of the impartiality of the translator, his faithfulness towards either of the Source or Target cultures, translator's version of the accurate description remain debatable.

Therefore, the present study attempts to succinctly clarify the position of the culture within the process of translation, the magnitude of impact on the translator and the readership, and the role of a translator to successfully overcome the obstacles posed by cultural distinctions during the process of translation. Hence, the present study would furnish a novel insight into the discourse on translation and culture via the translators' perspectives. Furthermore, the analysis would create a basis to refute a few traditional convictions on translation through logical, evidencesupported rationales. In the quest, the 


\section{Original Article}

paucity of the unit of analysis generates a limitation for generalization. Yet, the qualitative discourse along the diversified avenues of translation would conciliate the dearth in quantity.

\section{LITERATURE REVIEW}

The origins of translation practices could be traced back to the early dissemination of religious and cultural ideologies throughout the world, as translation constructed a conducive space for the newfound denominations and the teachings to reach their adherents. To name a few, the Bible, New Testament, and Buddhist scriptures were amongst the earliest religious translations. In the opinion of Sawant (2013), "the most significant turn in the history of translation came with the Bible translation" (p. 2). Consequently, the advancement of Greek and Latin literary cultures prompted distinguished writers to engage in translation for entertainment purposes. Livius Andronicus' translation of Odyssey into Latin as Odusia, making the epic accessible to Romans, was one such monumental translation in the history of translation.

The advancement of literary cultures and the utilitarian value of translation in the new world broadened the discourse on the discipline to hitherto unattended dimensions. Although the study of translation was initially relegated to an element of language learning and a discipline affiliated to comparative linguistics, the latter half of the twentieth century demonstrated an inclination towards more methodical and linguistic-oriented approaches to study translation as an independent discipline. J.C. Catford (1964), a pioneering scholar of the linguistic-based approach to translation, defined the process of translation as "the replacement of textual material in one language (S.L.) by equivalent textual material in another language (T.L.)" (p. 20). In this particular interpretation, it is evident that Catford has concentrated on textbased linguistic elements for defining the act of translation. Likewise, the structuralist Roman Jakobson (1959), who claimed that the factors governing translation are linguistic meaning and equivalence, suggested three ways of interpreting a verbal sign - "it may be translated into other signs of the same language, into another language, or into another, nonverbal system of symbols" (p. 233). The taxonomy is built on the distinctions between linguistic signs and their affiliated meanings.

The rapid development of translation in the 1980s inculcated a split from linguistic approaches to translation, refuting its prescriptive and constricted outlook. The diverging move was endorsed by the cultural paradigm, which spread across many disciplines at the time, prompting aficionados of translation to instigate a cultural shift in the discipline. 


\section{Original Article}

According to Bassnett (1990), the motive to expand the object of study was justified on the grounds "that translation plays a major role in shaping literary systems, that translation does not take place on a horizontal axis, that the translator is involved in complex power negotiations (mediating between cultures, as it were)" (p. 14). Furthermore, she claimed that "Once upon a time the questions that were always being asked were, how can translation be taught and how can translation be studied ... Now, the questions have been changed, the object of study has been refined; what is studied is text embedded within a network of both source and target culture signs" (ibid). The changing landscape of translation ensued via the cultural turn, hence, brought forth the realization that the field of translation extends beyond the immediacy of textual elements to incorporate extratextual elements.

Nida (2015), known for the translation of the Bible into various aboriginal languages, in an ethnological approach to the study of culture and translation, stated that "words are fundamentally symbols for the features of the culture" (p. 196). He further claimed that the cultural situation of both Source and Target Texts must be conveyed through the translation and to achieve that, "the words which designate the closest equivalent must be employed" (ibid). Based on the supposition Nida (2015) classified culture-specific equivalence problems of translation under (1) Ecology, (2) Material culture, (3) Social culture, (4) Religious culture, and (5) Linguistic culture. Utilizing the categorization, he expounded the precise correspondence across cultural information to the semantic problems encountered in translation - for instance, extracting one such circumstance from Biblical translation, he claimed that it is quite unaccommodating in tropical countries to render the word 'desert' as a place which lacks plant life for it is incomprehensible for a culture such as Maya Indian that any place on earth would not have vegetation unless it has been stripped completely to prepare for a maize -field and a clear field is not the cultural equivalent of the desert of Palestine culture referred in the Bible. Hence, "when some region is completely lacking in some topographical feature, it is frequently impossible to present exactly the feature of another region" (Nida, 2015, p. 197). Thus in the opinions of Nida (2015), in translating the ecological features specific to a particular culture, one must translate the concept 'desert' as 'an abandoned place' for culturally, the two concepts are equivalent in the sense that both places lack human population.

Similarly, in discussing the obstacles encountered in translating class and caste under social culture, Nida (2015) pinpointed that in most of the aboriginal languages, there is a dearth of designated terms for 'common 
people' as they are considered culturally insignificant due to their positioning within the lower levels of social hierarchy. In the Mayan culture of Yucatan, the social distinction is determined by the distance from the places inhabitants reside to the center of the town or village where the elite groups are occupied. Thus, the concept of 'common people' is interpreted as 'the people in the back part of the town' for lack of a cultural equivalent within the Maya culture (Nida, 2015, p. 200).

Peter Newmark (1988), referring to culture and translation in an anthropological sense, defined culture as "the way of life and its manifestations that are peculiar to a community that uses a particular language as its means of expression" (p. 94). He identified culture as an independent variable existing outside of the translation process. The translator should accommodate value to these cultural aspects by adopting different techniques in translation. Expounding on the inference, he stated, "thus paella is paella on most occasions, though it needs glossing when it is not known to the target language readership, either descriptively (as fish, chicken, rice, etc.) or connotatively (as the Spanish national dish) or generalizing (as the main course) if the particular dish is not important. Thus the range of choices for translation equivalents is narrower in cultural terms" (Newmark, 2001, p. 328).
Consequently, he claimed that when a particular speech community prioritizes a specific category, which he referred to ascultural focus, translation emerges due to the cultural gap (distance) or the overlap resulting amid the Source and Target Texts. For instance, in the food culture, one of the most sensitive cultural facets of the modern era, French are best known for fine wines and cheeses, Italians for their signature pizzas and pasta, Arabs for mansaf and mezza, and Indians for butter chicken and malai kofta whilst Sri Lanka is world-renowned for their rice and curry dishes which is a succulent assortment of rice, vegetables, meats, spices, and herbs. Frequently, a cultural gap remains amid such culture-bound food items, which poses a difficulty for the translator.

Hence, adapting the taxonomy of Nida, Peter Newmark (1988) classified culture in translation under (1) Ecology (2) Material culture; artifacts (3) Social culture; work and leisure (4) Organizations, customs, activities, procedures, concepts and (5) Gestures and habits. For instance, summarizing the category of gestures and habits, Newmark (1988) stated that;

For gestures and habits there is a distinction between description and function which can be made where necessary in ambiguous cases: thus, if people smile a little when someone dies, do a slow hand-clap to express warm appreciation, spit as a blessing, nod to dissent or 
shake their head to assent, kiss their fingertips to greet or to praise, give a thumb-up signal to ok, all of which occur in some cultures and not in others. (p. 103)

Newmark (1988) posited few general principles which govern the process of cultural translation, of which, the first being the most ardent task the translator is saddled with identifying the culture-specific concepts of the Source Text and granting the due recognition whilst respecting the cultural gaps and overlaps with the other cultures involved. The second principle is the availability of techniques to address the issues of cultural translation at the opposite ends of the spectrum. He located transference (emphasis on the culture and excludes the message) at one end. In contrast, componential analysis (highlights the message while undermining the culture) is located at the opposing end of the continuum. In between exists a plethora of techniques either steering towards the fundamental dynamics of transference or componential analysis. Newmark relates the motivation of the translator and the linguistic capacities of the audience as the third and fourth principles negotiating the role of culture in the process of translation.

In the discourse on translation methods, L. Venuti's in-depth analysis of domestication and foreignization persists at the forefront. Venuti (1995) explored the two dichotomies, which are direct products of the translator's manipulation of cultural attributes within a particular cultural situation. Venuti (1995) interpreted translation as the "forcible replacement of the linguistic and cultural difference of the foreign text with a text that will be intelligible to the target language" (p. 18). He elucidated that both source text and translation consist of a diverse cultural repertoire that neither the writer of the source text nor the translator invents and that inevitably leads to a conflict of interest in the act of translation. Nonetheless, to acquire the demanded output of a translation by the readership or the external entities privy to the process, the translator ought to adopt a method of translation which ensues the end goal - "the aim of the translation is to bring back cultural other as the same, the recognizable, even the familiar;" (p. 19).

German theologian and philosopher Friedrich Schleiermacher, in a lecture delivered on the topic of different methods of translation, argued that "there are only two. Either the translator leaves the author in peace, as much as possible, and moves the reader towards him; or he leaves the reader in peace, as much as possible, and moves the author towards him" (Venuti, 1995, p. 20). In other words, the translator should either prefer the domesticating method of translation, an ethnocentric reduction of the Source Text to the Target language cultural values, transporting the author back home or a foreignizing 
method, an ethno deviant stress on those cultural values to maintain the cultural distinctions of the original, sending the reader abroad.

Fundamentally, the two dichotomies are built upon the translator's behavior and maneuvering of the cultural gap and overlap amid the Source and Target languages. Scholars of translation advocate both methods of translation depending upon the strategic rendering of the translation and the position of the translator within the course of translation. For example, Venuti endorses a resistant translation strategy, which is quite synonymous with the foreignization method of translation, refuting the domestication on the basis that the deliberate transparent strategy adopted to reduce the strange elements of the foreign text might lead to the invisibility of the translator.

Hence, it is evident that cultural attributes are a decisive factor in the process of translation as it dominates not only the process of translation but also the methods of rendering a foreign text to a particular readership, the positioning of the translator within the target language conventions as well as the meta-narratives and scholarly narratives on translation.

\section{METHODOLOGY}

Adhering to a pre-designed research strategy, the conceptual design consisted of the major research objectives of the study - the 'what' and 'why.' Thus, to realize the positioning of culture within the process of translation and its' behavior, a group of individuals actively engaged in translation is chosen as the unit of analysis. The sample included two lecturers of translation, two freelance translators, and two graduates of translation. The individuals represented specialized knowledge in a range of translation types from Literary translation to Technical translation. The data were collected via a qualitative approach in which in-depth, semi-structured interviews were conducted. In the semi-structured interviews, which lasted around an hour, the participants were asked to describe their involvement in different types of translation, the process, and the cultural impact extensively to the best of their knowledge. The garnered data were evaluated and reviewed under the thematic analysis (T.A.) method, "which is a method for identifying and analyzing patterns of meaning in a dataset" (Braun and Clarke, 2012, p. 4). The analyzed data reflected a dual inductive/ deductive and latent/manifest set of themes, which explicitly affirmed the intricacy of the study. Moreover, secondary data selectively extracted from sources like books, journal articles, periodicals, and speeches apropos to the research study were employed to augment the outcomes of the study. 


\section{Original Article}

\section{RESULTS AND FINDINGS}

Culture governs the process of translation.

Dweik and Suleiman (2012), in surmising the findings of a research conducted on the problems encountered in translating cultural expressions from Arabic to English, stated that "the very name of culturespecific expressions or cultural expressions indicates the what and why of their problem. They are simply difficult to comprehend and/or translate because they are specific to a given culture in terms of their linguistic structure, semantic denotation and, more significantly, their socio-cognitive relevance" (p. 55). In a similar vein, a recurrent motif revealed and reiterated throughout the discussions by the participants was the ubiquitous issues of culture dictating the translation procedure. Participant two is of the opinion that, "culture and language are complementary of each other, and hence, each and every language situation is borne in a cultural context". In other words, a text is ultimately culture-bound and reflects the cultural reality of the particular community - "on the interaction between translation and culture, translation is not only a linguistic act but also a cultural one" (Braçaj, 2014, p. 332).

Participant three shares the same sentiments. In her opinion, translation is a twofold journey involving culture and language as they are inseparable, "two sides of the same coin". Furthermore, she stated that the semantic meaning of a particular linguistic unit couldn't be comprehended unless aligned with the respective cultural context. More specifically, the notion behind a written or spoken word is determined in their cultural interpretation. Thus, a text is a reflection of cultural practices inherent to a particular community. The participant provided a perfect example by way of a novel, in which the setting, plot, characters, themes, and even the idiosyncratic attributes of a writer and their manipulation of a language to narrate a story portray the elements of the culture which they are part of.

According to participant six, the cultural specificity of a text stymies a translator from directly translating a Source language text to the Target language. She stated that the translator has to concentrate on culture-specific concepts outside of the particular text to transfer the Source Text message without any distortion to the meaning. Hence, culture occupies a formidable position within the translation process.

Since a language is regarded as the verbal representation of a particular culture, the act of translation inevitably becomes an intercultural phenomenon. Regarding this close relationship amongst culture and translation, Snell -Hornby pointed that "the translatability of a text depends on the extent to which the text is embedded in its own specific 
culture and also on how far apart, concerning time and space, the S.T. and T.T. receivers are" (Braçaj, 2014, p. 334). The feasibility of a translation is instigated in its' relationship to culture. Thus, culture governs the process of translation, both explicitly and implicitly.

The myth: culture is a matter limited to Literary translation.

In hindsight, translation practices were initially instigated, concentrating upon the literary translation as the advancement of literary cultures encouraged both writers and translators to indulge in the translation of literature. Since then, literary translation has occupied a paramount stature within the discourse on translation. Translation of an esthetically structured text, combined with its' idiosyncratic writing patterns innate to a particular writer, is a relatively intricate task. The sui generis nature of an artistic work generated from the socio-cultural milieu it is rooted invariably cultivates attributes inherent to such environments. The uniqueness might appear relatively unfamiliar to an individual remote of the respective culture. Consequently, there is a conviction that matters pertaining to culture are mostly prevalent within literary translation compared to other types of translations.

Nonetheless, the participants who frequently engage in different types of translation, including literary translation, refuted the claim that cultural translation is visible solely in the translation of literature. Instead, the participants exclaimed that culture and the accompanying complications exist in almost all the texts, including the most -technical, such as religious, scientific, and legal. Participant one stated that "culture is everywhere". From the daily musings to religious observances and home remedies, cultural elements could be discovered in the most mundane tasks. As such, it is part and parcel of every text, irrespective of its genre and origins.

Participant five debunked the widely discussed standpoint through a pragmatic aspect, which is relevant to the translation of legal texts. He stated that 'Thesawalami', the laws and customs practiced by the Tamil populace of Sri Lanka, is entwined with the cultural practices of the Tamils, which showcase attributes inherent to the respective culture. In translating legal documents pertaining to such laws, the translator ought to understand the legal aspects and the cultural dimensions. On the same account, the legal practice adopted in Sri Lanka is an amalgamation of Roman-Dutch law, English law, and customary law. The laws built upon different faiths and doctrines and different traditions and norms contain practices inherent to their own community, which incorporate cultural dimensions to the translation of legal documents. 


\section{Original Article}

Thus, it is evident that cultural connotations exist external to literary translations, as they are not just limited to works of fiction. For E. Nida (1964), "the person who is engaged in translating from one language into another ought to be constantly aware of the contrast in the entire range of culture represented by the two languages" (p. 90). The concept of an entire range of cultures varies from culture to culture as languages are equipped and lexicalized in a myriad of ways collating different interpretations. For instance, in Russian interpretation, 'conscience' refers to the presence of a God in an individual's soul, while the Englishspeaking lot consider the concept as awareness of good and evil. The Arab Muslims, too, share the perspective of the Russians, addressing the concept as a religious connotation. From their standpoint, god is an ever-present entity in an individual's life. In contrast, to an English person, the concept represents a moral or ethical guideline outside of the realms of religion. Thus, the attribution of a cultural value to a concept depends upon the interpretation within the associated language and cultural situation, not on its' positioning, relativity, or genre.

The unattainable equivalence in translation

Throughout the interviews conducted, the participants reiterated the concept of equivalence as the most intricate element accompanying culture in translation. The act of translation inevitably involves an equivalence situation. In the opinions of Vinay and Darbelnet (2015), equivalence refers to "replicating the same situation as the original while using completely different wording" (para. 3). In other words, equivalence attempts to create a replica of the Source Text in the Target language. Although a plethora of criticisms have been aimed at the theory of equivalence, it is regarded as one of the most significant indicators in determining the success of a translation.

Nevertheless, in translating the culture, equivalence in translation is virtually unattainable. According to participant three, achieving cultural equivalence in translation is "impossible". The inherent features of culture-specific concepts create a considerable challenge to the translator. Mona Baker (1992) defined a culture-specific concept as a "situation where the source language word may express an unknown concept in the target language. The concept in question may be abstract or concrete; it may relate to a religious belief, a social custom, or even a type of food" (p. 21). Thus, from the meals prepared to enrich one's taste palate to clothing donned, social institutions and styles of communication culture-specific concepts demonstrate a manifold of features that lack an equivalent in a culture different from the original. For instance, the condiments used to add a depth of 
flavor in preparing succulent dishes in Sri Lankan cuisine might appear unfamiliar to an outsider. Simultaneously, the vocabulary employed by the laymen to address their highly revered Buddhist monks is in stark contrast to the everyday conversations. Such differences in cultures create a hiatus impossible to bridge for the translators.

Similarly, participants two, four and five, elaborated on the difficulties in acquiring cultural equivalence in translation. According to the translators, cultural equivalence in translation is "an ideal situation" far beyond the expectations of translators. Lack of cultural awareness of both the Source and Target cultures leads to ultimate failure in equivalence, in their opinion. For instance, participant five stated that the translator should be aware of the cultural diversity within a particular group of population. $\mathrm{He}$ noted that the cultural practices, norms, and traditions differ with geographical and topographical differences, not just community wise; hence, the translator should be aware of every nuance, behavior, and motive behind the actions of an individual in both source and target cultures to gain equivalence in translation, which is inconceivable and impractical.

Participant one identified the issue of equivalence on lexical levels, including word and semantic levels. In brief, she identified equivalence above word level as the most challenging element. At the semantic level, she associated proverbs, idioms, clichés, nominal and adjective phrases which are originated from a particular culture as the elements with a higher impact. For example, an idiomatic expression could not be translated literally from one language to another without altering the meaning. It frequently contains a cultural reference-the cultural allusion within the idiomatic expression results in a challenge to the translator. The idiomatic expression 'as mad as a hatter' originated from the real-life practice of hatters around $17^{\text {th }}$ century England which has its' reference to the cultural situation at the time could be considered a perfect example. Thus, to transfer the contextual meaning with an appropriate equivalent, the translator requires an in-depth understanding of the respective cultures. Attaining cultural equivalence, therefore, creates a massive hurdle for the translator during the process of translation.

\section{Position of the translator}

When inquired about the standpoint of the translators with relevance to the translation of culture, essentially in overcoming the aforementioned dilemmas, the participants provided a wide range of techniques and methods they practice, at least to achieve a partial -equivalence. An outstanding factor amongst the techniques mentioned was that they refer to a broad spectrum consisting of strategies ranging from one end of the scale to another. Particularly, the techniques adopted by each individual translator 
reflected their inclination/ faithfulness towards either of the texts; the source text, or the target text. Peter Newmark (1988) surmised the principle undermining the scenario as follows:

Two translation procedures which are at opposite ends of the scale are normally available; transference, which usually in literary texts, offer local color and atmosphere, and in specialized texts enables the readership to identify the referent particularly a name or concept - in other texts (or conversations) without difficulty. However, transference, though it is brief and concise, blocks comprehension, emphasizes the culture and excludes the message, does not communicate; some would say it is not a translation procedure at all. At the other end, there is componential analysis, the most accurate translation procedure, which excludes the culture and highlights the message. (p. 96)

Venuti (1995) delineated the opposing strategies as domestication and foreignization depending upon the translator's approach to the translation of culture-specific elements within the text. Specifically, if the translator adopts a translation strategy that is fluent and transparent, removing the obstacles of unfamiliarity, the method is identified as domestication which molds a clear and distinctive mosaic to the target audience. In contrast, if the translator retains the foreign elements within the Target Text, deliberately preferring to ignore the conventional methods, the strategy is identified as the foreignization method.

There was a clear distinction amongst the participants with relevance to their choice of strategy in translation. The approaches ranged from transference, cultural equivalents, descriptive equivalents, transonym, literal translations, synonomy, modulation, neologisms, paraphrases, cultural footnotes to shift semantic notion and deliberate omission. Nevertheless, most of the participants highlighted that in translating foreign language texts to Sinhalese, they prefer domestication methods, where culture-specific concepts inherent to the Source language are mostly adapted and interpreted to the comprehension of the Target audience. For instance, participant six stated that while translating an article regarding proverbs and their usage, she resorted to using cultural equivalents in Sinhalese, as direct or literal translations are nonsensical in the Target language. She attributed the strategy to Sinhalese being their first language/ mother tongue.

On the contrary, participants three and five claimed that domestication strategies aren't always possible or compatible. Explaining the quandary, participant three stated that translating a Japanese text on Halloween traditions to Sinhalese is not a facile task due to the culture-specific concepts embedded in the tradition. Hence, frequently the translator has to 
employ loan words or 'translate as it is to avoid distortion to the source culture meaning of the relevant concepts. Participant five emphasized the culture-sensitive concepts as an example of such situations of translation where a complete adaptation to the target culture is impossible. For instance, only a few homosexuals or transgender-related terms consist of an equivalent in Sinhalese. When confronted with a term lacking a direct equivalent, the translator has to either borrow a term, paraphrase or incorporate cultural footnotes.

Hence, it is evident that the translators choose to translate culture in parallel with the demands of the text they are involved in the act of translation. Thus, the cultural situation, the intercultural differences, and the space for adaptability influence the choice of translation. For instance, certain cultures resemble culturally similar situations, whereas some cultures are worlds apart in their respective dimensions. The magnitude allows space for the translator to either adapt accordingly or refrain from drastic divergences. The oriental cultures bore certain similarities in their cultural situations rather than with the occidental cultures with their westernized elements of culture. Furthermore, the translator has to concentrate upon the logical sequences in writing. Maintaining consistency and logical flow while interpreting culture-specific concepts is paramount for a successful translation. Subsequently, the cultural and linguistic comprehension of the target audience should be considered, as the interpretation of culture should be within the readers' capacity to add value to the translation.

\section{CONCLUSION}

The contact amongst two different cultural systems inevitably leads to a confrontation amid two heterogeneous value systems deeply embedded within the respective communities. The translator, who is intervening on a primary and secondary basis as a mediator in minimizing the lacuna existing amid the two cultures, should thus resolve the clash of cultural entities by preserving the cultural homogeneity with minimal distortion to the respective cultural dimensions. How does the translator continue to do so? The analyzed data of the study reveal translators' perspectives regarding the particular bone of contention and the approaches adopted to overcome the matters as an effective cross-cultural mediator. In the process, the choice of translation, including the position of the translator, the methods, and the extent of adaptation, depend upon the requirements or the demands of the text and cultural situation in consideration. The space for interpretation, the linguistic capacity, and the cultural homogeneity of the involved cultures influence the act of translation both explicitly and 
implicitly. Hence, the role of the translator as a cultural -mediator is influenced by many extra-textual factors outside the primary act of translation involving the texts.

\section{ACKNOWLEDGMENT}

A special thanks to all the participants for their valuable time and cooperation.

\section{References}

Baker, M. (1992). In Other Words: A Coursebook on Translation. Routledge: London.

Bassnett, S. (1990). Translation, History and Culture. Pinter Publishers: U.K.

Bracaj, M. (2014). Reflection on Language, Culture and Translation and Culture as a Challenge for Translation Process. Retrieved January 13, 2021, from https://studylib.net/doc/11944195/reflecti on-on-language--culture-andtranslation-and-culture

Braun, V., \& Clarke, V. (2012). Thematic Analysis. A.P.A. Handbook on Research psychology, 2, Retrieved from https://www.researchgate.net/publicatio n/269930410_Thematic_analysis

Catford, J.C. (1964). A Linguistic Theory of Translation. Glasgow: Oxford University Press.

Dweik, B.S., \& Suleiman, M. (2012) Problems encountered in Translating cultural expressions from Arabic into English. International Journal of English Linguistics, 3-5, Retrieved from http://www.ccsenet.org/journal/index.p hp/ijel/article/view/30644

Jahoda, G. (2012). Critical Reflections on some recent definitions of Culture. Culture and Psychology. 18-3, pp. 289-303. Retrieved from www.cap.sagepub.com
Jakobson, R. (1959). The Translation Studies Reader. In L. Venuti (Ed.), London: Routledge.

Newmark, P. (1988). A Textbook of Translation. New York: Prentice-Hall.

Newmark, P. (2001). Translation and Culture. Translation and meaning, 5, Retrieved from

https://www.translationdirectory.com/ar ticles/article1507.php

Nida, E. (2015). Linguistics and Ethnology in Translation-problems. Word, 1-2, Retrieved from https://www.tandfonline.com/doi/pdf/1 0.1080/00437956.1945.11659254

Nida, E. (1964). Toward a Science of Translating. Leiden: E.J. Brill.

Sawant, D.G. (2013). History of Translation. Retrieved January 21, 2021, from https://studylib.net/doc/25253573/dattag.-sawant-historyoftranslation

Simak, B., Yahya, W.R.W., \& Babee, R. (2014). Creativity, Culture and Translation. English Language Teaching, 7-6, Retrieved from

https://www.academia.edu/8565291/Creativi ty_Culture_and_Translation._English_Lan guage_Teaching_Vol._7_No._6_2014

Venuti, L. (1995). The Translator's Invisibility. London: Routledge.

Walinki, J.T. (2015). Translation Procedures. Retrieved December 20, 2020, from https://www.researchgate.net/publicatio n/282504599_Translation_Procedures

Wang, F. (2014). An Approach to Domestication and Foreignization from the Angle of Cultural translation. Retrieved January 12, 2021, from https://pdfs.semanticscholar.org/b7b1/aa 53b24e6d964e84326cfaf0066e2462e9d6.p df 